(c) Н.Ю. Пшеничная, А.А. Плоскирева, В.Г. Акимкин, И.А. Лизинфельд, Г.Ю. Журавлев, 2020

Н.Ю. Пшеничная, И.А. Лизинфельд, Г.Ю. Журавлев, А.А.Плоскирева, В.Г. Акимкин

\title{
ЭПИДЕМИЧЕСКИЙ ПРОЦЕСС COVID-19 В РОССИЙСКОЙ ФЕДЕРАЦИИ: ПРОМЕЖУТОЧНЫЕ ИТОГИ. СООБЩЕНИЕ 2.
}

ФБУН «Центральный научно-исследовательский институт эпидемиологии» Роспотребнадзора, Москва, Россия

\section{PЕЗЮMЕ}

Цель исследования. Промежуточный анализ компонентов эпидемического процесса COVID-19 в Российской Федерации, связанных с контактными лицами и вторичными случаями инфекции.

Материалы и методы. Выполнен анализ 190856 первичных случаев COVID-19 и 146996 контактных с ними лиц на основании отдельных данных мониторинга, проводимого Роспотребнадзором за январь-июнь 2020 г. Дана характеристика эпидемических очагов, контактных лиц с первичными случаями COVID-19 и вторичных случаев инфицирования.

\section{Результаты.}

Наибольший удельный вес контактных лиц выявлен у первичных больных с легкой формой COVID-19 - 50,02\%. На пациентов со среднетяжелой формой пришлось 45,40\% контактов, тяжелой - 4,58\%. Пациенты с более легким течением COVID-19, имели большее число контактов, что, соответственно, приводило большему вторичных случаев инфекции.

В возрастной группе 41-64 лет наблюдался как наибольший процент первичных пациентов с COVID-19 - 44,42\%, так и соответственно контактных с ними лиц - 44,51\%. На возраст 18-40 лет приходилось 30,20\% заболевших и 34,21\% контактных лиц. Удельный вес несовершеннолетних пациентов в возрасте от 0-6 лет составил 2,70\%, 717 лет - 4,02\% заболевших и, соответственно этим возрастным группам, 1,94\% и 3,13\% контактных лиц.

Контакты в бытовых очагах, занимали ведущее значение в трансмиссии вируса во всех возрастных группах. Основную роль в передаче инфекции в эпидемических 
очагах различной локализации играли больные в возрасте от 40 до 64 лет. Удельный вес пациентов этой возрастной группы составил 42,02\% в социальных учреждениях, $43,40 \%$ в быту и $47,70 \%$ в очагах по месту работы.

\section{Заключение.}

Наибольшее число контактов и соответственно вторичных случаев инфекции приходится на больных в возрасте от 18 до 64 лет с легкими и средне-тяжелыми формами заболевания. Контакты в бытовых очагах играют основную роль в передаче COVID-19 во всех возрастных группах. В возрасте от 18 до 64 лет важное значение имеет также трансмиссия инфекции по месту работы. Среди больных преобладают во всех очагах инфекции лица в возрасте 40-64 года. Полученные данные помогут оптимизировать меры по противодействию COVID-19.

Ключевые слова: эпидемический процесс, возрастные группы, степень тяжести, контакты, COVID-19, Россия, бытовые очаги,

N. Yu. Pshenichnaya, I. A. Lizinfeld, G. Yu. Zhuravlev, A. A. Ploskireva, V. G. Akimkin,

\section{COVID-19 EPIDEMIC PROCESS IN THE RUSSIAN FEDERATION: INTERIM RESULTS. 2th REPORT}

Federal Budgetary Institution of Science "Central Research Institute of Epidemiology" of Rospotrebnadzor, Moscow, Russia

\section{ABSTRACT}

Keywords: epidemic process, age groups, severity, COVID-19, Russia.

\section{Введение.}

Раннее выявление случаев любого инфекционного заболевания и, как следствие, своевременное и тщательное отслеживание контактов является одним из первостепенных компонентов в борьбе со вспышками, эпидемиями и пандемиями инфекционных заболеваний, в том числе, COVID-19 [1,2].

В борьбе с пандемией COVID-19 следует уделять особое внимание выявлению контактных с больными COVID-19 лиц в различных эпидемических очагах, сборе информации о возможных контактах с больным COVID-19, отслеживанию и наблюдению за ними, особенно за людьми, входящими в группу риска по тяжелому 
течению заболевания, организации лабораторных обследований, предоставлению информации в центры по мониторингу за этим заболеванием. Выявление и отслеживание контактных лиц играет ключевую роль в сдерживании распространения инфекционного заболевания в менее затронутых регионах и закрытых социальных учреждениях, таких как тюрьмы, дома престарелых, детские дома, больницы и др.

Отслеживание контактов является важной мерой для борьбы с продолжающейся эпидемией COVID-19 в сочетании с другими мерами, принимаемыми в Российской Федерации [3, 4].

C начала эпидемического процесса COVID-19 в России проводится регистрация и тщательный мониторинг больных с этой инфекцией, а также контактных с ними лиц. Анализ данных о контактных с пациентами с COVID-19 может являться одним из критериев планирования и проведения мер по сдерживанию распространения инфекции и оценки их эффективности.

На 1 июля 2020 года база мониторинга Роспотребнадзора содержала информацию о 574149 тысяч пациентов с COVID-19 и 247108 контактных с ними.

Цель исследования. Промежуточный анализ компонентов эпидемического процесса COVID-19 в Российской Федерации, связанных с контактными лицами и вторичными случаями инфекции.

Материалы и методы. Выполнен анализ 190856 первичных случаев COVID-19 и 146996 контактных с ними лиц на основании отдельных данных мониторинга, проводимого Роспотребнадзором за январь-июнь 2020 г. Дана характеристика эпидемических очагов, контактных лиц с первичными случаями COVID-19 и вторичных случаев инфицирования.

\section{Результаты}

Распределение контактных лиц и вторичных случаев COVID-19 в зависимости от тяжести заболевания у первичных пациентов.

Данные о степени тяжести заболевания в форме мониторинга были указаны у 190856 больных COVID-19. Легкая степень тяжести выявлена у 50,02 \% больных. Удельный вес контактных лиц с этими пациентами был также наибольший - 50,56\%; средняя степень тяжести заболевания определена у 45,40\% первичных больных с COVID-19, на долю контактов с ними пришлось 45,80\%. Пациенты с тяжелой формой инфекции составили 4,58\%, с ними контактировало 3,63\% человек. Наибольшее число 
контактных лиц у которых в последующем был выявлен COVID-19 (54,22\%) также приходилось на легкую форму инфекции у первичных пациентов, 42,43\% - на среднетяжелую и тяжелую, соответственно - 42,43\% и 3,35\% (Табл.1). Соотношение контактных лиц и вторичных случаев заболевания при легкой форме инфекции у первичных пациентов составило 3,07:1, при средне-тяжелой и тяжелой - 3,56:1. Таким образом, основную роль в распространении инфекции играли первичные пациенты с легкими формами COVID-19.

Таблица 1

Распределение контактных лиц и вторичных случаев в зависимости от степени тяжести заболевания первичных пациентов

\begin{tabular}{|c|c|c|c|c|c|c|}
\hline \multirow[t]{3}{*}{$\begin{array}{l}\text { Группы } \\
\text { контактных лиц }\end{array}$} & \multicolumn{6}{|c|}{$\begin{array}{c}\text { Удельный вес контактных лиц и вторичных случаев в } \\
\text { зависимости от степени тяжести заболевания у первичных } \\
\text { пациентов }\end{array}$} \\
\hline & \multicolumn{2}{|c|}{ Легкая (1) } & \multicolumn{2}{|c|}{ Средне-тяжелая (2) } & \multicolumn{2}{|c|}{ Тяжелая (3) } \\
\hline & Абс. & $\mathrm{M} \pm \mathrm{m}, \%$ & Абс. & $\mathrm{M} \pm \mathrm{m}, \%$ & Абс. & $\mathrm{M} \pm \mathrm{m}, \%$ \\
\hline $\begin{array}{l}\text { Все больные } \\
(n=190856)\end{array}$ & 95469 & $50,02 \pm 0,12$ & 86653 & $45,40 \pm 0,12$ & 8734 & $4,58 \pm 0,05$ \\
\hline $\begin{array}{l}\text { Все контактные } \\
\text { лица (n=146996) }\end{array}$ & 74319 & $50,56 \pm 0,13$ & 67344 & $\begin{array}{l}45,81 \pm 0,13 \\
\%\end{array}$ & 5333 & $3,63 \pm 0,05$ \\
\hline $\begin{array}{l}\text { контактные, у } \\
\text { которых выявлен } \\
\text { COVID-19 } \\
\text { (44591) }\end{array}$ & 24177 & $54,22 \pm 0,23$ & 18918 & $42,43 \pm 0,23$ & 1496 & $3,35 \pm 0,09$ \\
\hline
\end{tabular}

Зависимость возраста первичных пациентов, количества контактов и вторичных случаев COVID-19

Наибольшее количество первичных случаев COVID-19 было зарегистрировано в 2-х возрастных диапазонах - возрасте от 18-40 и от 41 до 64 лет (Рис.1). Суммарно 
они составили 74,62\% от всех анализируемых пациентов. На долю этих двух групп пришлось, соответственно, наибольшее количество контактов $(78,72 \%)$ и вторичных случаев инфекции (75,97\%). Максимальное число заболевших (44,42 $\pm 0,13 \%)$, контактных $(44,51 \pm 0,06 \%)$ и вторичных случаев $(42,05 \pm 0,19 \%)$ наблюдалось в возрасте 41-64 лет. Возрастная группа 18-40 лет занимала 2-е место по всем этим параметрам:

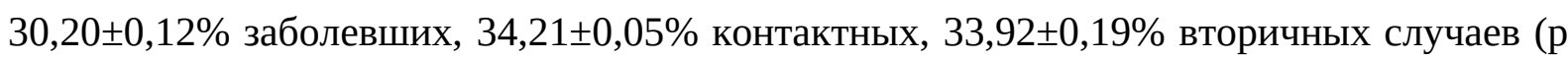
во всех случаях <0,001). В то же время, в возрасте 65 лет и старше количество заболевших, и, соответственно, контактных и вторичных случаев, значительно снижалось в сравнении с предыдущими возрастными группами. В группе несовершеннолетних пациентов в возрасте от 0-6 лет и 7-17 лет число заболевших, контактных и вторичных случаев COVID-19 было минимальным (Рис.1).

Низкий процент инфицированных и контактных с ними лиц у детей и лиц пожилого возраста (65+) демонстрирует эффективность ограничительных мероприятий, направленных на максимальное исключение этих возрастных групп из эпидемического процесса COVID-19.

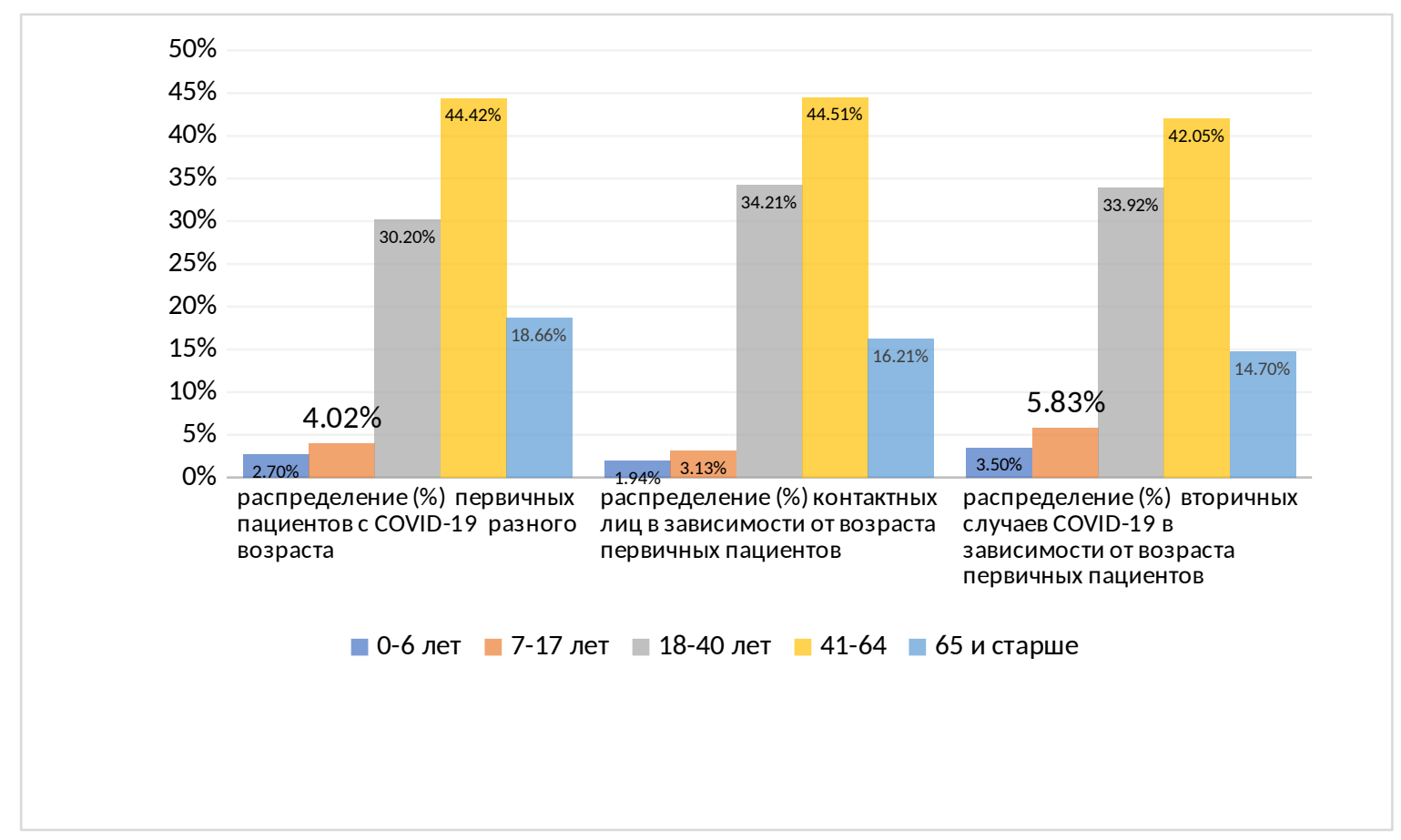

Динамика регистрации первичных случаев COVID-19, контактных с ними лиц и вторичных случаев инфекции в марте-июне 2020

В ежемесячной динамике эпидемического процесса COVID-19 видна четкая взаимосвязь числа первичных случаев COVID-19, контактных с ними лиц и вторичных случаев инфекции (Рис.2). В мае 2020 года, когда в России было отмечено наибольшее 
число ежедневно выявляемых новых случаев заболевания, было выявлено и наибольшее количество контактных лиц. Нарушение режима самоизоляции во время майских праздников привело к резкому увеличению количества контактов с первичными больными и, соответственно, вторичных случаев заболевания.

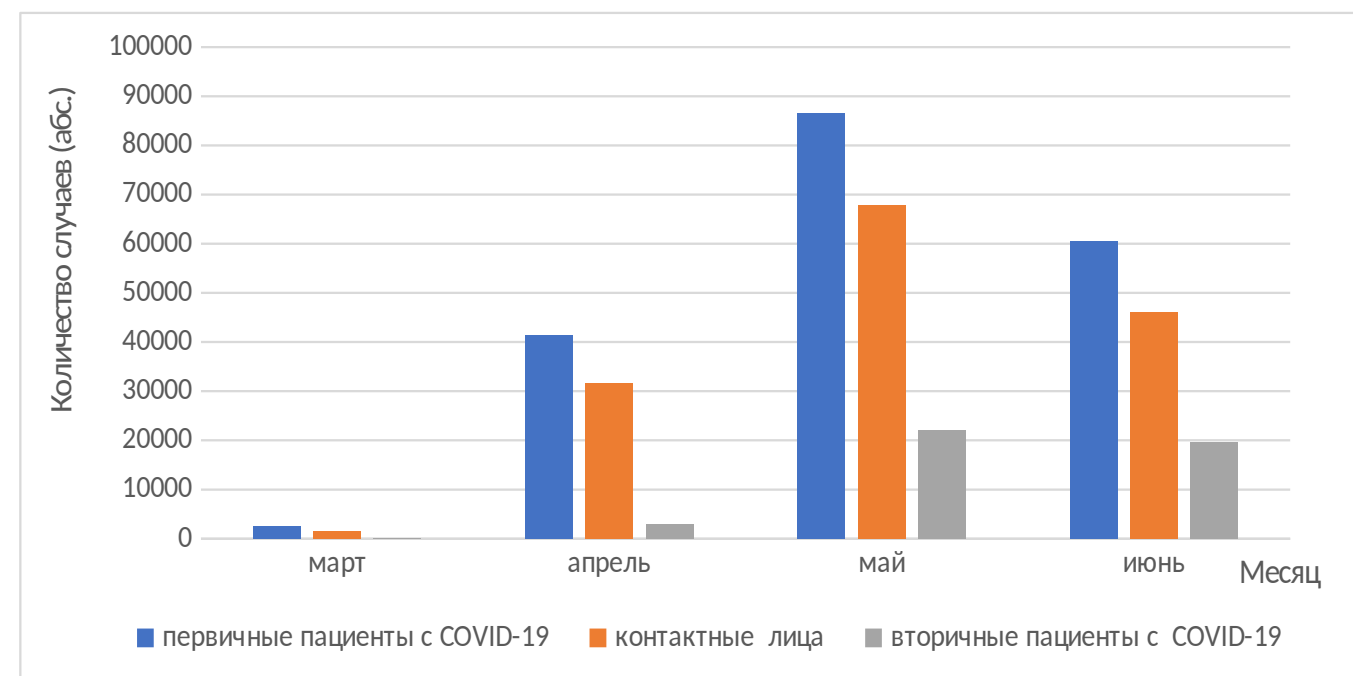

Рисунок 2. Распределение первичных пациентов с COVID-19, контактных с ними лиц и вторичных случаев по месяцам ( март - июнь 2020)

В июне прослеживается соблюдение режима самоизоляции и проводимых ограничительных мероприятий, что отразилось, на существенном снижении числа контактов и вторичных случаев инфицирования.

Локализация эпидемических очагов в зависимости от возраста первичных пациентов с COVID-19

Анализ эпидемических очагов показал, что наибольший процент контактов в быту наблюдался у детей и подростков (0-17 лет) - 65,98\% и лиц возрасте 65 лет и старше $(65,18 \%)$.

В возрасте 18-40 лет и 41-64 лет немаловажную роль играли контакты по месту работы, составившие $9,00 \%$ и 9,01\%.

У пожилых лиц (65 лет и старше) чаще, чем в других возрастных группах имели место контакты в медицинских (7,07\%) и социальных учреждениях (5,98\%) (Рис.3). 
Контакты в образовательных учреждениях, интернатах, общежитиях и др. имели основное значение у детей и подростков 0-17 лет и составляли 5,78\% от всех контактов в этой возрастной категории. Контакты на транспорте и в других организованных коллективах составляли во всех возрастных категориях от 5,10\% до $5,53 \%$.

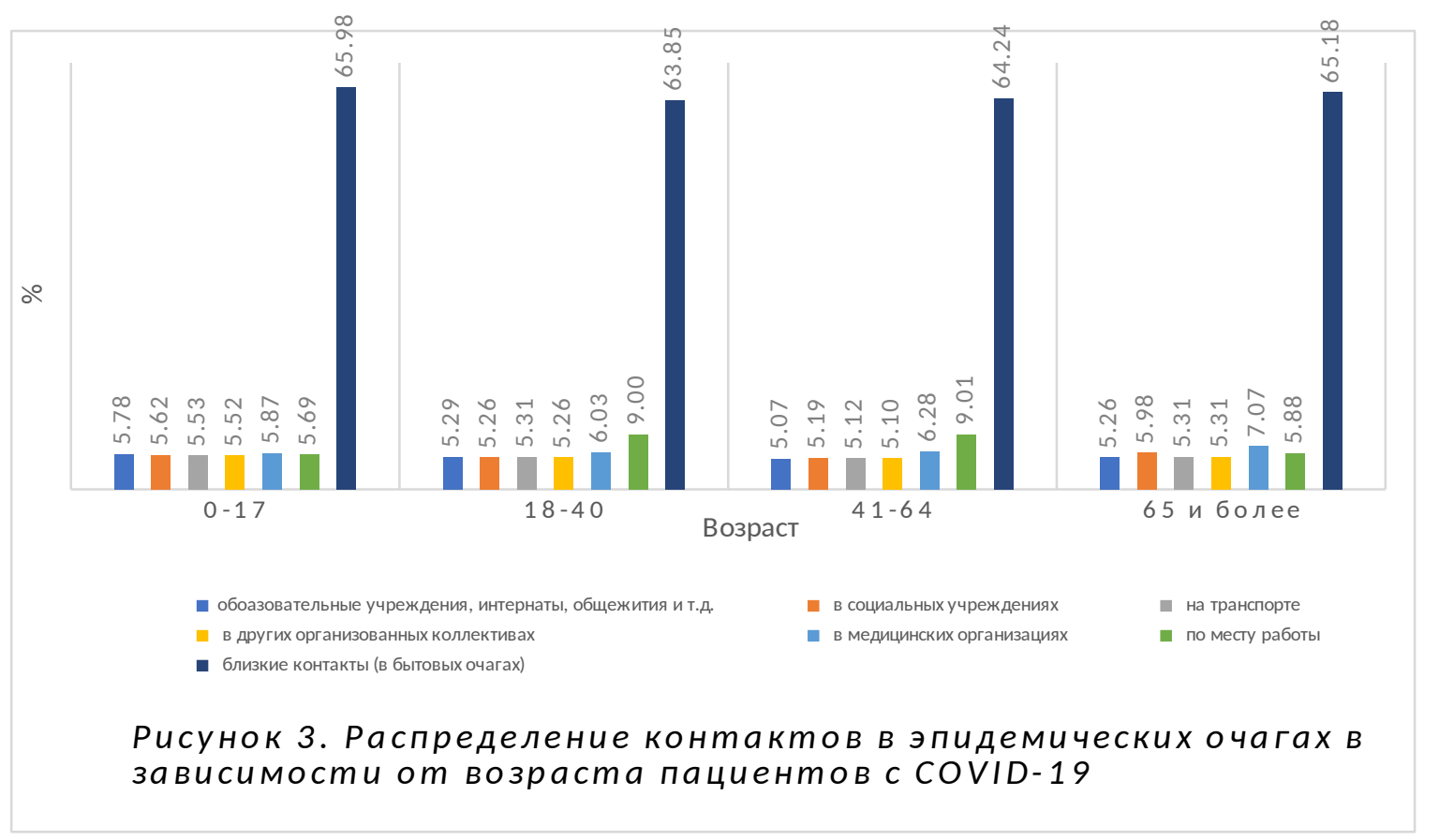

Основную роль в передаче инфекции в эпидемических очагах различной локализации играли больные в возрасте от 40 до 64 лет, составляя от 42,02\% в социальных учреждениях до 47,70\% в очагах по месту работы, за ними шла возрастая категория 18-40 лет, на которую приходилось от 30,59\% в очагах в медицинских организациях до 34,94\% в очагах по месту работы. 3-е место по удельному весу во всех эпидемических очагах составили пациенты в возрасте 65 лет и старше с максимумом в медицинских $(17,45 \%)$ и социальных $(17,27 \%)$ учреждениях. Дети и подростки 0-17 лет находились на последнем месте по удельному весу приходящихся на эту возрастную группу контактов. Удельный вес этой возрастной группы отмечен в образовательных учреждениях, интернатах, общежитиях и др. (10,00\%) и в других организованных коллективах (9,58\%). 


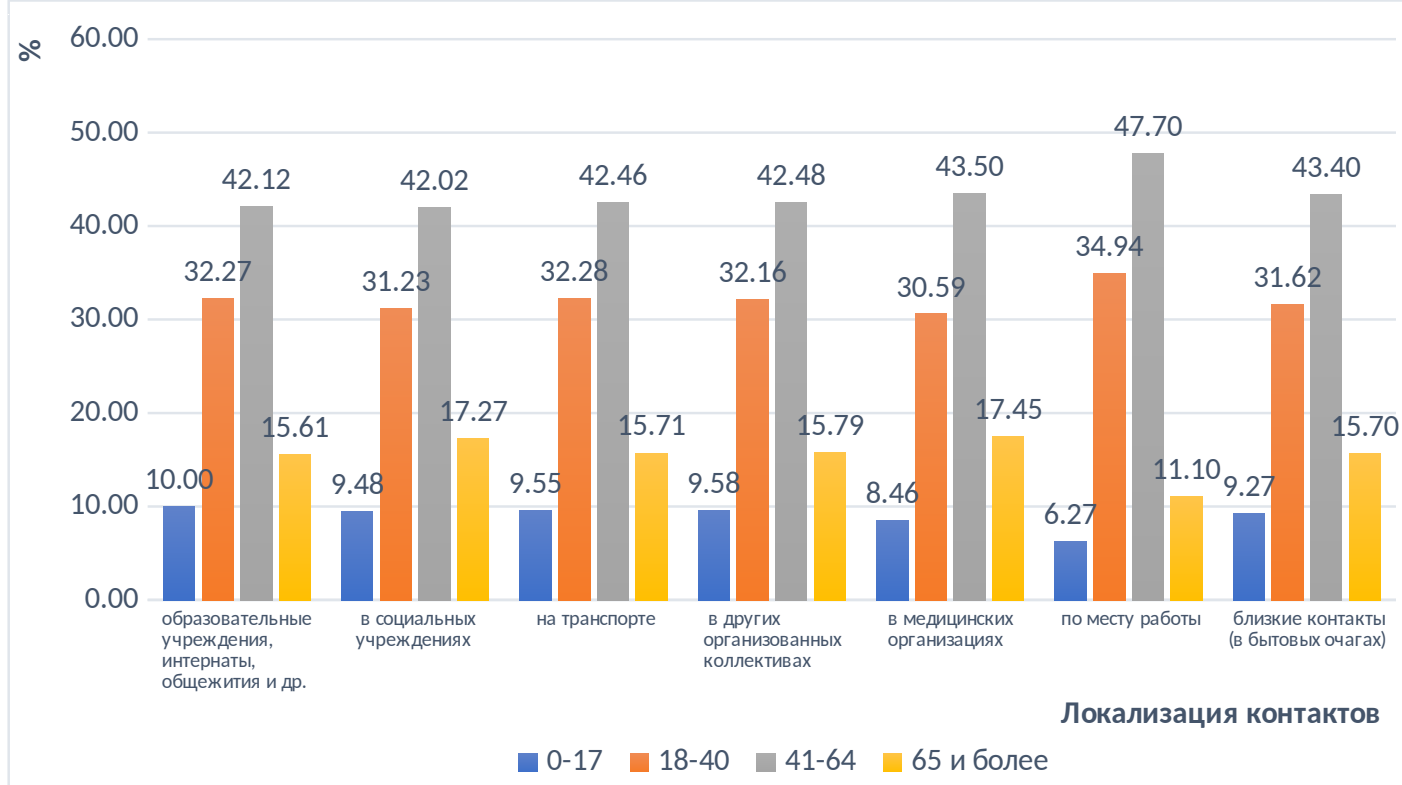

Рисунок 4. Удельный вес пациентов с COVID-19 различного возраста в эпидемических очагах различной локализации

\section{Обсуждение результатов}

Опыт ряда стран показывает четкую взаимосвязь между жесткими ограничительными мероприятиями, пониманием и осознанием их необходимости обществом и снижением числа контактных лиц и вторичных случаев инфекции при соблюдении режима самоизоляции и правильном выполнении профилактических мероприятий $[5,6]$. В период пандемии как никогда важно тесное взаимодействие правительства, различных министерств и ведомств, общества, средств массовой информации и волонтерского движения для борьбы с распространением коронавирусной инфекции COVID-19.

В Китае резкому перелому хода эпидемии способствовали жесткие ограничительные меры, введенные государством, экстренная всеобъемлющая диверсификация всех медицинских ресурсов и наращивание дополнительного медицинского потенциала, введения жесткого инфекционного контроля не только в ЛПУ, но и на транспорте, во всех общественных местах, а также беспрецедентная социальная мобилизация населения [5] Ученые КНР показали, что отслеживание контактных лиц и их изоляция сокращают время, в течение которого больные с COVID-19 представляют опасность для окружающих, тем самым снижая репродуктивное число вируса. Однако общее влияние отслеживания контактов и 
изоляции является неопределенным и сильно зависит от числа бессимптомных случаев. Кроме того, дети также подвержены риску заражения, хотя крайне редко переносят заболевание в тяжелой форме, поэтому их также следует учитывать при анализе передачи инфекции и контроля над ней [6].

Пример Китая, показывает, что карантин, социальное дистанцирование и изоляция больных могут сдерживать эпидемию. Такие меры удалось принять в Сингапуре и Гонконге. В обоих странах COVID-19 на сегодняшний день хорошо контролируется благодаря ранним действиям правительства и мерам социального дистанцирования [7, 8]. В США и Италии ограничительные меры по борьбе с COVID19 были введены с большим опозданием, что способствовало стремительному росту числа больных и, соответственно, контактных лиц, распространению инфекции в учреждениях закрытого типа [9, 10].

В Российской Федерации с самого начала эпидемических проявлений COVID-19 взят курс на реализацию стратегии «опережающего реагирования», в соответствии с которой принимались все противоэпидемические меры. С целью недопущения завоза COVID-19 в Российскую Федерацию мероприятия по мониторингу эпидемиологической ситуации начаты уже 31 декабря 2019 г. и, по мере ухудшения эпидемиологической обстановки в странах мира, дифференцировано вводились ограничения на въезд, вплоть до прекращения выдачи виз для всех иностранных граждан [3]. Данные меры позволили снизить темпы роста числа больных, прибывших из-за рубежа. Мероприятия, направленные на борьбу с передачей инфекции внутри страны, также реализовывались по опережающему типу реагирования и вводились поэтапно с учетом развития эпидемического процесса в регионах [10].

Анализ данных мониторинга пациентов с COVID-19, контактных с ними лиц и вторичных случаев заболевания показывает, что передача инфекции через контакты в бытовых очагах занимает ведущее значение в трансмиссии вируса во всех возрастных группах. Поэтому, санитарно-просветительная работа среди населения о путях передачи вируса и мерах предосторожности в семье должна проводиться на регулярной основе, ориентируясь на различные возрастные группы.

В группах несовершеннолетних пациентов число заболевших, а следовательно, и контактных с ними лиц было минимальным, что отражало эффективность перевода образовательных учреждений на дистанционное обучение. Низкий процент заболевших среди людей пожилого возраста (65+) демонстрирует эффективность рекомендаций по 
самоизоляции, переводу на дистанционный режим или оформления отпуска у этого контингента из группы риска по тяжелому течению COVID-19.

На больных в возрасте 18-64 лет с легким течением COVID-19 приходится максимальное число контактов и, соответственно, вторичных случаев инфекции. У лиц данного возраста, помимо контактов в быту, немаловажное значение имеет передача инфекции по месту работы. Основной фокус карантинных мер должен быть сосредоточен на этих наиболее мобильных и вовлеченных в эпидемический процесс группах населения. Учреждения должны продолжать придерживаться удаленного режима работы для максимально возможного числа работников. На тех предприятиях, где дистанционная работа невозможна, должны соблюдаться все рекомендованные меры, направленные на прерывание путей передачи инфекции (социальное дистанцирование, масочный режим, гигиена рук и т.д.).

Массовые нарушения ограничительного режима во время майских праздников привели к резкому увеличению количества контактных, а, следовательно, и вторичных случаев инфекции. С другой стороны, они наглядно продемонстрировали действенность ограничительных мер, введенных на территории Российской Федерации с конца марта 2020 и последствия их нарушений.

\section{Заключение}

Мировой опыт показывает, что введение ограничительных мероприятий, мониторинг и изоляция контактных с больными COVID-19 лиц ведёт к снижению новых случаев заболевания и уменьшению вторичных случаев заражения COVID-19.

Российская стратегия борьбы с новой коронавирусной инфекцией подтверждает целесообразность и эффективность одновременного введения жестких ограничительных мероприятий, самоизоляции определенных контингентов, отслеживания и изоляции контактных лиц, так и мер профилактики инфекции, направленных на предотвращение распространения COVID-19.

Четкое правительственное и межведомственное взаимодействие в совокупности с гражданской ответственностью привели к значительному снижению интенсивности эпидемического процесса COVID-19 на территории Российской Федерации.

Опыт России по противодействию COVID-19 может быть использован при разработке плана мероприятий по противодействию возможной второй волне 
пандемии, а также другими станами мира, в которых наблюдается высокая активность эпидемического процесса этого инфекционного заболевания.

\section{Конфликт интересов/Conflict of interest}

Авторы заявляют об отсутствии возможных конфликтов интересов.

The authors declare no possible conflicts of interest.

\section{Литература/References}

1. Hellewell J, Abbott S, Gimma A, Bosse NI, Jarvis CI, Russell TW, Munday JD, Kucharski AJ, Edmunds WJ; Centre for the Mathematical Modelling of Infectious Diseases COVID-19 Working Group, Funk S, Eggo RM. Feasibility of controlling COVID-19 outbreaks by isolation of cases and contacts. Version 2. Lancet Glob Health. 2020 Apr;8(4): e488-e496. doi: 10.1016/S2214-109X (20)30074-7. Epub 2020 Feb 28. Erratum in: Lancet Glob Health. 2020 Mar 5: PMID: 32119825; PMCID: PMC7097845.

2 European Centre for Disease Prevention and Control. Contact tracing: public health management of persons, including healthcare workers, having had contact with COVID-19 cases in the European Union - second update, 8 April 2020. Stockholm: ECDC; 2020.

3 Распоряжение Правительства РФ от 16.03.2020 N 635-р (ред. от 24.07.2020) <O временном ограничении въезда в Российскую Федерацию иностранных граждан и лиц без гражданства и временном приостановлении оформления и выдачи виз и приглашений Собрание законодательства Российской Федерации, 2020, N 12, ст. 1825; N 14, ст. 2145; N 19, ст. 3025; N 21, ст. 3314

4 Постановление Главного государственного санитарного врача Российской Федерации "Об утверждении санитарно-эпидемиологических правил СП 3.1.3597-20 "Профилактика новой коронавирусной инфекции (COVID-19)".

5. Семенов А.В., Пшеничная Н.Ю. Рожденная в Ухане: уроки эпидемии COVID19 в Китае. Инфекция и иммунитет. 2020; 10 (2): 210-220. https://doi.org/10.15789/22207619-BIW-1453

6. Bi Q, Wu Y, Mei S, Ye C, Zou X, Zhang Z, Liu X, Wei L, Truelove SA, Zhang T, Gao W, Cheng C, Tang X, Wu X, Wu Y, Sun B, Huang S, Sun Y, Zhang J, Ma T, Lessler J, Feng T. Epidemiology and transmission of COVID-19 in 391 cases and 1286 of their close contacts in Shenzhen, China: a retrospective cohort study. Lancet Infect Dis. 2020 Apr 27:S1473-3099(20)30287-5. doi: 10.1016/S1473-3099(20)30287-5. Epub ahead of print. 
Erratum in: Lancet Infect Dis. 2020 Jul;20(7):e148. PMID: 32353347; PMCID: PMC7185944.

7. Anderson, Roy M., et al. "How will country-based mitigation measures influence the course of the COVID-19 epidemic?." The Lancet 395.10228 (2020): 931-934.

8. Landau R, Bernstein K, Mhyre J. Lessons learned from first COVID-19 cases in the United States. Anesthesia \& Analgesia. 2020 Jul 1;131(1): e25-6.

9. Salathé, Marcel; Althaus, Christian L; Neher, Richard; Stringhini, Silvia; Hodcroft, Emma; Fellay, Jacques; Zwahlen, Marcel; Senti, Gabriela; Battegay, Manuel; Wilder-Smith, Annelies; +3 more... (2020) COVID-19 epidemic in Switzerland: on the importance of testing, contact tracing and isolation. Swiss medical weekly, 150 (11-12). w20225-. ISSN 1424-7860 DOI: https://doi.org/10.4414/smw.2020.20225

10 Кутырев В.В., Попова А.Ю., Смоленский В.Ю., Ежлова Е.Б., Демина Ю.В., Сафронов В.А., Карнаухов И.Г., Иванова А.В., Щербакова С.А. Эпидемиологические особенности новой коронавирусной инфекции (COVID-19). Сообщение 1: Модели реализации профилактических и противоэпидемических мероприятий. Проблемы особо опасных инфекций. 2020;(1):6-13. https://doi.org/10.21055/0370-1069-2020-1-6-13

\section{Сведения об авторах:}

Пшеничная Наталья Юрьевна - д.м.н., профессор, зам. директора по клинико-аналитической работе ФБУН «Центральный научно-исследовательский институт эпидемиологии» Роспотребнадзора, Москва, Россия; e-mail: nataliapshenichnaya@yandex.ru; ORCID: http://orcid.org/0000-0003-2570-711X;

Плоскирева Антонина Александровна - д.м.н., зам. директора по клинической работе ФБУН «Центральный научно-исследовательский институт эпидемиологии» Роспотребнадзора, Москва, Россия; e-mail: antoninna@mail.ru; ORCID: https://orcid.org/0000-0002-3612-1889;

Акимкин Василий Геннадиевич - академик РАН, д.м.н., профессор, директор ФБУН «Центральный научно-исследовательский институт эпидемиологии» Роспотребнадзора, Москва, Россия; e-mail: crie@crie.ru; ORCID: https://orcid.org/00000003-4228-9044;

Лизинфельд Ирина Александровна -консультант организационнометодического отдела ФБУН «Центральный научно-исследовательский институт эпидемиологии» Роспотребнадзора, Москва, Россия; e-mail: irinalizinfeld@gmail.com; https://orcid.org/0000-0002-8114-1002; 
Журавлев Григорий Юрьевич - ординатор по специальности «Инфекционные болезни» ФБУН «Центральный научно-исследовательский институт эпидемиологии» Роспотребнадзора», Москва, Россия, e-mail: grigory.y.zhuravlev@gmail.com, https://orcid.org/0000-0003-2467-7000

\section{Information about authors:}

Natalia Yu. Pshenichnaya, DSci., Prof; Deputy Director on clinical and analytical work of the Central research Institute of Epidemiology of Rospotrebnadzor, Moscow, Russia; e-mail: natalia-pshenichnaya@yandex.ru; ORCID: http://orcid.org/0000-0003-2570711X;

Antonina A. Ploskireva - DSci., Deputy Director of clinical work of the Central research Institute of Epidemiology of Rospotrebnadzor, Moscow, Russia; e-mail: antoninna@mail.ru; ORCID: https://orcid.org/0000-0002-3612-1889;

Vasily G. Akimkin - academician of the Russian Academy of Sciences, DSci., Prof., Central Research Institute of Epidemiology of Rospotrebnadzor, Moscow, Russia; email: vgakimkin@yandex.ru; ORCID: https://orcid.org/0000-0003-4228-9044;

Irina A. Lizinfeld - MD, Consultant of the organizational and methodological department of the Central Research Institute of Epidemiology of Rospotrebnadzor, Moscow, Russia; e-mail: irinalizinfeld@gmail.com; https://orcid.org/0000-0002-8114-1002;

Grigory Yu.Zhuravlev - MD, resident - physician of the Central Research Institute of Epidemiology of Rospotrebnadzor, Moscow, Russia; e-mail: grigory.y.zhuravlev@gmail.com, https://orcid.org/0000-0003-2467-7000 